\title{
Purification, partial characterization and role in lipid transport to developing oocytes of a novel lipophorin from the cowpea weevil, Callosobruchus maculatus
}

\author{
A.A. Ximenes, G.A. Oliveira, P. Bittencourt-Cunha, M. Tomokyo, D.B. Leite, \\ E. Folly, D.M. Golodne and G.C. Atella
}

Instituto de Bioquímica Médica, Centro de Ciências da Saúde, Universidade Federal do Rio de Janeiro, Rio de Janeiro, RJ, Brasil

Correspondence to: G.C. Atella, Instituto de Bioquímica Médica, CCS, UFRJ, Bloco H, ㄴo andar, Av. Bauhínia, 400, Ilha do Fundão, 21941-590 Rio de Janeiro, RJ, Brasil

Fax: +55-21-2270-8647. E-mail: atella@Bioqmed.ufrj.br

\begin{abstract}
Lipid transport in arthropods is achieved by highly specialized lipoproteins, which resemble those described in vertebrate blood. Here we describe purification and characterization of the lipid-apolipoprotein complex, lipophorin (Lp), from adults and larvae of the cowpea weevil Callosobruchus maculatus. We also describe the Lp-mediated lipid transfer to developing oocytes. Lps were isolated from homogenates of $C$. maculatus larvae and adults by potassio bromide gradient and characterized with respect to physicochemical properties and lipid content. The weevil Lp (465 kDa) and larval Lp (585 kDa), with hydrated densities of 1.22 and $1.14 \mathrm{~g} / \mathrm{mL}$, contained 34 and $56 \%$ lipids and 9 and $7 \%$ carbohydrates, respectively. In both Lps, mannose was the predominant monosaccharide detected by paper chromatography. SDS-PAGE revealed two apolipoproteins in each Lp with molecular masses of $225 \mathrm{kDa}$ (apolipoprotein-I) and $79 \mathrm{kDa}$ (apolipoprotein-II). The lipids were extracted and analyzed by thinlayer chromatography. The major phospholipids found were phosphatidylserine, phosphatidylcholine and phosphatidylethanolamine in adult Lp, and phosphatidylcholine, phosphatidylethanolamine and sphingomyelin in larval Lp. Hydrocarbons, fatty acids and triacylglycerol were the major neutral lipids found in both Lps. Lps labeled in the protein moiety with radioactive iodine ( ${ }^{125}$ /-iodine) or in the lipid moiety with fluorescent lipids revealed direct evidence of endocytic uptake of Lps in live oocytes of $C$. maculatus.
\end{abstract}

Key words: Callosobruchus maculatus; Lipophorin; Lipid transport; Oogenesis; Hydrocarbons

Research supported by CNPq, PADCT, Pronex, International Foudation for Science (IFS), and FAPERJ.

Received April 2, 2007. Accepted September 24, 2007

\section{INTRODUCTION}

Cowpea (Vigna unguiculata) is a leguminous crop cultivated in most tropical regions, where its seeds contribute to human and animal diets as an important source of carbohydrates and protein. Insects from the order Coleoptera (family Bruchidae) cause serious losses of cowpea and other seeds in storage. One of the most important insect pests of the cowpea is the larva of Callosobruchus maculatus (Coleoptera: Bruchidae), which avidly attacks the seeds during storage. Studies of Coleoptera in general and bruchids in particular are underrepresented in insect biochemistry, despite the fact that Coleoptera is the largest insect order. Additionally, most biochemical research on beetles has concentrated on the description of digestive enzymes (1). A detailed description of the lipid metabolism of these organisms is lacking.

In insects, lipophorins (Lps) are the major hemolymphatic lipoproteins, which carry and distribute lipids of many classes among the tissues involved in lipid absorption, storage and utilization (2). Lps contain two apolipoproteins, 
apolipophorin I (apoLp-I, $\sim 250 \mathrm{kDa}$ ) and apolipophorin II (apoLp-II, $\sim 80 \mathrm{kDa}$ ), which comprise about $60 \%$ of the mass of the particle (3). A third apoprotein (apolipophorin III, apoLp-III), of molecular mass about $17 \mathrm{kDa}$, is present in adults of some species in a molecular ratio that depends on physiological state of the insects (4).

Lps have been suggested to function as a shuttle for the transport of most of the lipid classes in the hemolymph (5). The best-known transport system is that of diacylglycerol (6). Insects capable of sustained flight use lipids as their main energy source. Lp particles transfer diacylglycerols to flight muscles and can then return to the fat body to be reloaded with diacylglycerol, thus acting as a reusable shuttle (5).

Insect oogenesis is another physiological process that also requires lipids. This process is characterized by a rapid accumulation of proteins and lipids by the growing oocytes and the production of a great number of eggs in a relatively short period of time. This process is very complex and the involvement of several organs coordinated by hormones has been recognized (7). In this process, Lp is the main lipoprotein responsible for lipid delivery to oocytes. Evidence for the role of $L p$ as the major vehicle for lipid transport to the oocytes was first provided by Chino et al. (8) in Philosamia cynthia (Lepidoptera). In Manduca sexta (Lepidoptera), Kawooya and Law (9) showed that low-density lipophorin unloads its lipids to the ovaries and then returns to the hemolymph. In addition, high-density lipophorin was also found to transfer lipids, resulting in its conversion to very high-density lipophorin, but without a recycling of apoproteins to the hemolymph (10).

In the present study, we purified and characterized the lipophorin from adults and larvae of the cowpea weevil $C$. maculatus. The biochemical role of this lipoprotein in the lipid transfer process is discussed.

\section{MATERIAL AND METHODS Insects}

A C. maculatus colony was maintained on cowpea seeds under standard conditions $\left(28^{\circ} \mathrm{C}\right.$ and $80 \%$ relative humidity, with a photoperiod of 12-h light/12-h dark).

\section{Lipophorin purification}

Adults or larvae $(4 \mathrm{~g})$ were homogenized using a tissue grinder (Thomas Scientific, Swedesboro, NJ, USA) in an ice bath in the presence of $20 \mathrm{mM}$ glutathione, $5 \mathrm{mM}$ EDTA, $2 \mathrm{mM}$ PMSF, $0.5 \mu \mathrm{g} / \mu \mathrm{L}$ antipain, $5 \mu \mathrm{M}$ pepstatin, and 0.5 $\mu \mathrm{g} / \mu \mathrm{L}$ leupeptin in PBS (10 mM phosphate, $0.15 \mathrm{M} \mathrm{NaCl}$, $\mathrm{pH}$ 7.4). The homogenate was then centrifuged at 100,000 $g$ for 30 min at $4^{\circ} \mathrm{C}$ in a Beckman ultracentrifuge (Optima L90 ultracentrifuge, Beckman Coulter, Palo Alto, CA, USA) to remove insoluble material. Potassium bromide $(\mathrm{KBr})$ was added to the supernatant to a final concentration of 0.4 $\mathrm{g} / \mathrm{mL}$ and this mixture was again centrifuged at $125,000 \mathrm{~g}$ in a Beckman ultracentrifuge (Optima L-90 ultracentrifuge, Beckman Coulter) with a fixed-angle Beckman rotor ( $\mathrm{Ti}$ 50.2 ) at $4^{\circ} \mathrm{C}$ for $20 \mathrm{~h}$. The gradient of $\mathrm{KBr}$ was fractionated from the top to the bottom and Lp fractions (1-4 from the top) were pooled, extensively dialyzed against PBS and stored under liquid nitrogen until use. The degree of purification was monitored by SDS-PAGE and protein concentration was estimated by the method of Lowry et al. (11) and the micro-BCA Kit (Pierce, Rockford, IL, USA) in the presence of $0.5 \%$ SDS, using bovine serum albumin as a standard.

\section{Polyacrylamide gel electrophoresis and molecular mass determination}

Polyacrylamide slab gels were run under both denaturing (with SDS) (12) and nondenaturing conditions (13). Electrophoresis was performed at constant voltage (100 V) on Tris-glycine gradient gels of $3-20 \%$ acrylamide, and the protein bands were stained with Coomassie blue. For molecular mass determinations, the molecular weight standard Rainbow Kit from Amersham (Buckinghamshire, England) was used.

The molecular mass of Lp was determined by a porelimiting gradient PAGE (3-20\%) as described by Nichols et al. (14). The gels were run at $100 \mathrm{~V}$ for $24 \mathrm{~h}$. Calibration standards used were thyroglobulin (669 kDa), apoferritin (440 kDa), catalase (232 kDa), and bovine serum albumin (66 kDa). The size calibration was based on nonhydrated particle sizes of the standard proteins calculated from the molecular weight and partial specific volume of the proteins, assuming spherical shape (14).

\section{Lipid analysis}

Lipid extraction was performed by the method of Bligh and Dyer (15) for $2 \mathrm{~h}$ in a stoppered tube in $5 \mathrm{~mL}$ chloroform-methanol-water solution $(2: 1: 0.8, v / v)$, with intermittent shaking. The mixture was centrifuged at $1500 \mathrm{~g}$ for 30 min at $4^{\circ} \mathrm{C}$ in a Sorvall RC-5b preparative centrifuge (Sorvall Centrifuge, Newtown, CT, USA), the supernatant was collected and the pellet subjected to a second lipid extraction $(1 \mathrm{~h})$. To the pooled supernatants, $5 \mathrm{~mL}$ water and $5 \mathrm{~mL}$ chloroform were added, the mixture was shaken and, after centrifugation, the organic phase was removed and dried under nitrogen. The content of total lipids was determined gravimetrically. Extracted lipids were analyzed by onedimensional thin-layer chromatography (TLC) for neutral lipids (16), or by two-dimensional TLC for phospholipids (17). To visualize the lipids, the plates were immersed for 
$10 \mathrm{~s}$ in a charring solution consisting of $3 \% \mathrm{CuSO}_{4}$ and $8 \%$ $\mathrm{H}_{3} \mathrm{PO}_{4}(\mathrm{v} / \mathrm{v})$ and heated to $110^{\circ} \mathrm{C}$ for $10 \mathrm{~min}$ (18). The charred TLC plates were then subjected to densitometric analysis. Each lipid spot was identified by comparison with lipid standards (Sigma Aldrich Co., St. Louis, MO, USA), run in parallel.

\section{Carbohydrate analysis}

Total carbohydrate was determined colorimetrically by the sulfuric acid/phenol method (19) using glucose as a standard. To a $400-\mu \mathrm{L}$ solution, $20 \mu \mathrm{L} 80 \%$ phenol (w/v) was added. Then, $1 \mathrm{~mL}$ concentrated sulfuric acid was added rapidly and the tubes were allowed to stand for 10 $\min$. The absorbance was measured at $490 \mathrm{~nm}$ for hexoses and compared to a standard curve prepared with various amounts of a $1-\mathrm{mg} / \mathrm{mL}$ glucose solution. The carbohydrate composition was analyzed by descending paper chromatography in isobutyric acid-ammonium hydroxide-water $(3: 2: 1, \mathrm{v} / \mathrm{v})$ using Whatman No. 1T paper. Subsequently, the chromatograms were dried and stained with silver nitrate (20).

\section{Lipophorin density determination}

The density of Lps was determined by the method of Coelho et al. (21). The purified Lp was added to a PBS solution containing $44 \%(\mathrm{w} / \mathrm{v}) \mathrm{KBr}$, to a final volume of 5 $\mathrm{mL}$. This solution was transferred to a centrifuge tube, overlaid with $5 \mathrm{~mL}$ PBS and centrifuged for $20 \mathrm{~h}$ in a Beckman $40 \mathrm{Ti}$ apparatus at $125,000 \mathrm{~g}$ at $4^{\circ} \mathrm{C}$. After centrifugation, the gradient was fractionated and the density of each fraction was measured using the refractive index of $\mathrm{KBr}$ at $25^{\circ} \mathrm{C}$.

\section{Lipophorin labeling}

Purified Lp was labeled with fluorescent fatty acid (BODIPY ${ }^{\circledR} \mathrm{FL} \mathrm{C}_{16}$ ) or phospholipids (TRITC-DHPE; Molecular Probes Inc., Eugene, OR, USA) using the method described by Martin-Nizard et al. (22). Distribution of the fluorescent lipids and Lp was observed using the methods described by Atella and Shahabuddin (23).

Following manufacturer instructions for radiolabeling (Sigma, St. Louis, MO, USA), purified Lp was iodinated with ${ }^{125}$ /-iodine (100 mCi/mL; Amersham, Piscataway, NJ, USA), using $200 \mathrm{mCi} / \mathrm{mg}$ protein. The iodogen (Pierce) was used at a concentration of $100 \mathrm{mg} / \mathrm{mg}$ protein. Free iodine was removed using Sephadex G-50 spin columns.

\section{Lipophorin uptake by ovaries}

Radio ${ }^{125}$-iodine-labeled Lp was injected (1 $\left.\mu \mathrm{g} / \mathrm{insect}\right)$ into the hemolymph of one-day-old vitellogenic females at $28^{\circ}$ or $4^{\circ} \mathrm{C}$ using a PLI-100 microinjector (Harvard Appara- tus, Holliston, MA, USA). At the desired time, the ovaries were dissected in medium 199 (Sigma-Aldrich Co.), washed and incubated for $30 \mathrm{~min}$ at $28^{\circ} \mathrm{C}$ in $1 \mathrm{~mL}$ of the same culture medium. The radioactive ovaries were homogenized in $0.15 \mathrm{M} \mathrm{NaCl}$ and the radioactivity was estimated by gamma counting. Alternatively, Lp labeled with either fluorescent fatty acids or fluorescent phospholipids was injected (10 $\mu \mathrm{g} / \mathrm{insect})$ into the hemolymph of vitellogenic females at $28^{\circ} \mathrm{C}$. One day after injection, the oocytes were dissected and examined with a fluorescent Axioscope microscope (Carl Zeiss, Inc., Thornwood, NJ, USA).

\section{RESULTS}

The soluble protein fraction from homogenates of larvae and adults of $C$. maculatus was subjected to a $\mathrm{KBr}$ gradient ultracentrifugation and the fractions were analyzed by SDS-PAGE (Figure 1). The fractions at the top in both gradients contained only Lp, consisting of two apolipoproteins, apoLp-I and apoLp-II, with molecular masses of 225 and $79 \mathrm{kDa}$, respectively. ApoLp-III (18 kDa) was visualized in larvae but not in adults (Figure 2D). Porelimiting gradient PAGE experiments indicated a molecular mass of $480 \mathrm{kDa}$ for adult Lp and of $585 \mathrm{kDa}$ for larval Lp (Figure 2C).

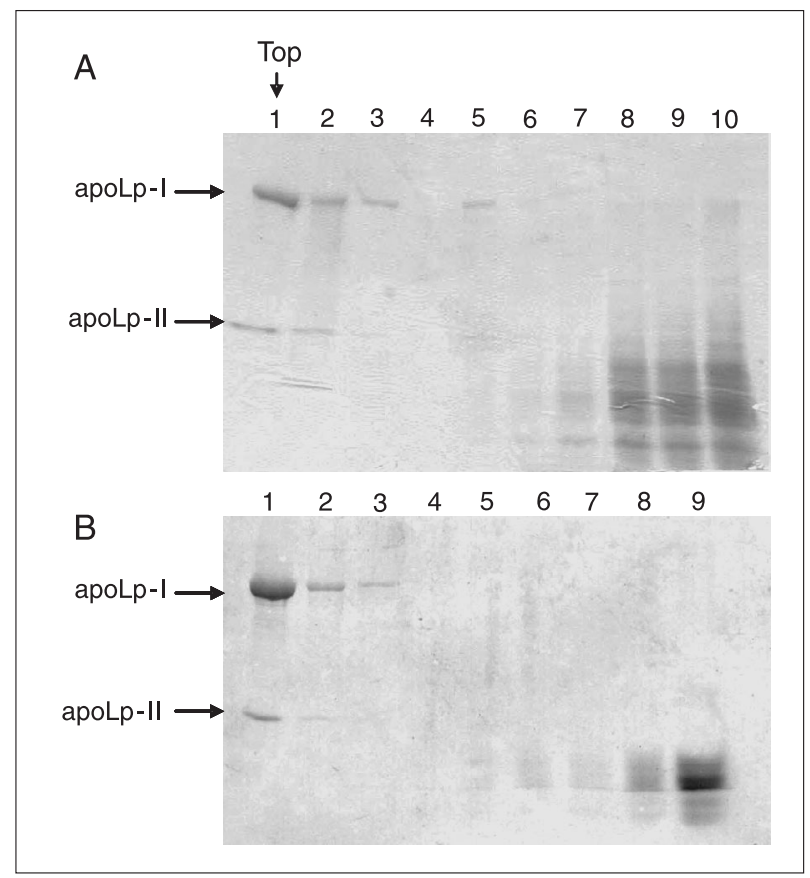

Figure 1. Purification of Callosobruchus maculatus lipophorin $(L p)$. Adults (A) or larvae (B) were homogenized and Lp was purified by $\mathrm{KBr}$ gradient ultracentrifugation as described in Material and Methods. The fractions ( 1 to 10 ) were subjected to SDSPAGE (3-20\%) and the proteins stained with Coomassie blue. ApoLp-I = apolipophorin I; apoLp-II = apolipophorin II. 
Table 1 shows the biochemical composition of the purified C. maculatus Lps. The adult Lp contained $57 \%$ protein and $34 \%$ lipid and had a high sugar content (9\%). The total lipid content of larval Lp (56\%) was much higher than that of adult Lp, but the carbohydrate content was similar (7\%). The C. maculatus Lps stained positively with the periodic acid-Schiff reagent for the presence of carbohydrates (data not shown) and mannose was the only sugar detected by paper chromatography in either case (Figure 2B).
Table 1. Chemical composition (\%, w/w) of adult and larval lipophorins from the cowpea weevil Callosobruchus maculatus.

\begin{tabular}{lrr}
\hline & Adult lipophorins & Larval lipophorins \\
\hline Protein (\%) & $56.7 \pm 2.8$ & $37.7 \pm 1.9$ \\
Neutral sugars (w/w) & $9.1 \pm 1.1$ & $7.2 \pm 1.1$ \\
Lipid (\%) & $34.2 \pm 1.5$ & $55.1 \pm 2.4$ \\
Neutral lipids (\%) & $89.2 \pm 1.3$ & $79.1 \pm 1.3$ \\
Phospholipids (\%) & $10.8 \pm 2.0$ & $20.9 \pm 1.0$ \\
\hline
\end{tabular}

Data are reported as means \pm SEM for four determinations.

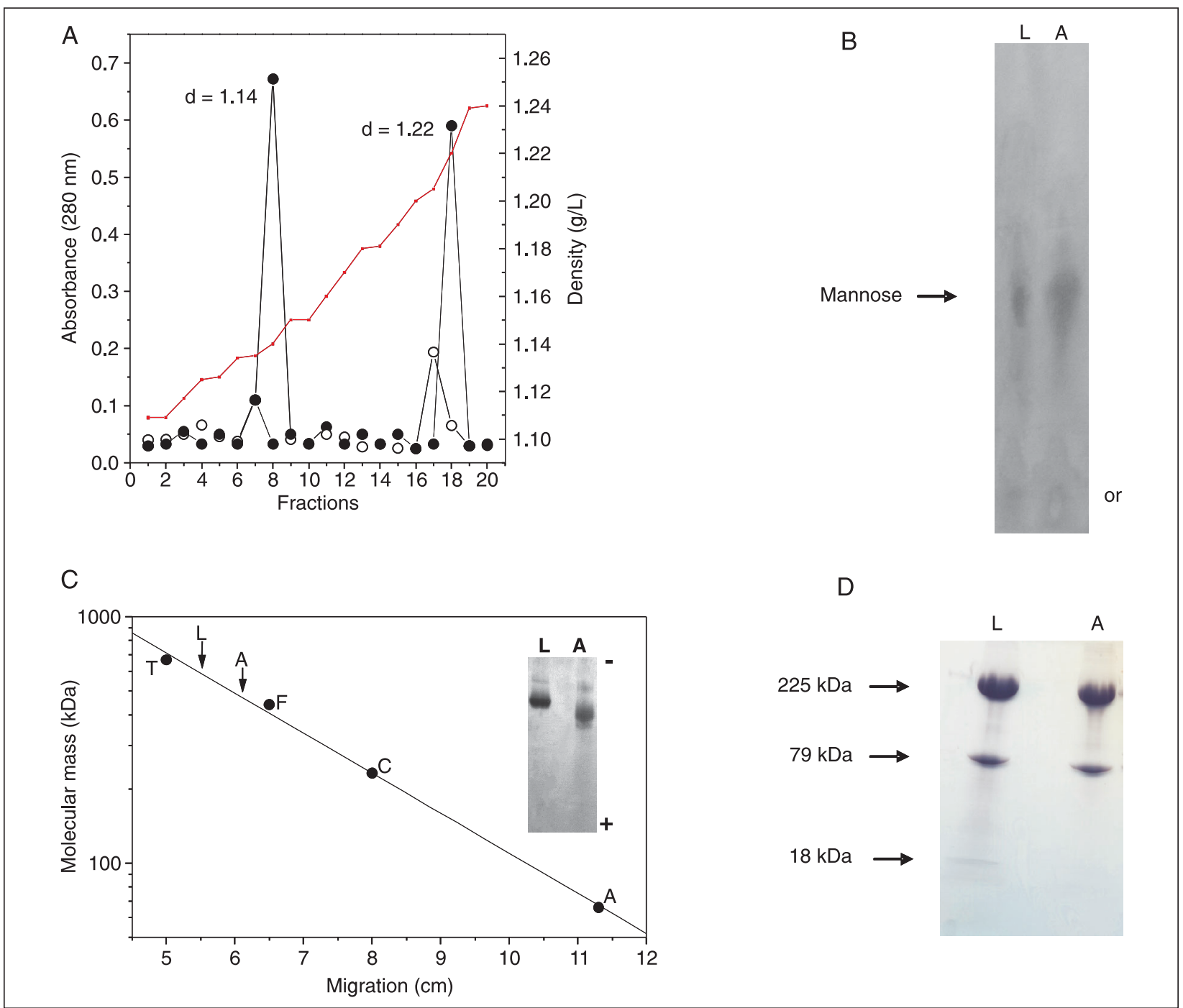

Figure 2. Biochemical properties of Callosobruchus maculatus lipophorin (Lp). A, Determination of Lp density. Lp from adults (filled circles) and larvae (open circles) was purified using $\mathrm{KBr}$ gradient ultracentrifugation. The density (d) of each Lp was measured with a refractometer (red line) and the amount of protein estimated at $280 \mathrm{~nm}$. B, Carbohydrate analysis of Lp. The carbohydrate composition of adult $(A)$ and larval $(L) L p$ was analyzed using paper chromatography. or $=$ origem. $C$, Determination of $L p$ molecular mass. $L p(30 \mu \mathrm{g})$ obtained from adults $(A)$ and larvae $(L)$ was subjected to a pore-limiting PAGE. Thyroglobulin (T), apoferritin (F), catalase (C), and bovine serum albumin (A) were used as molecular mass standards. $D$, Analysis of apolipophorin-III amounts of larval and adult Lp by a gradient SDS-PAGE (6-22.5\%). Other experimental details are described in Material and Methods. 
Lp purified from adults showed a density of $1.22 \mathrm{~g} / \mathrm{mL}$, whereas larval $L p$ had a density of $1.14 \mathrm{~g} / \mathrm{mL}$ (Figure 2A). These values were based on the density of $\mathrm{KBr}$, calculated from the refractive index of each fraction of a $\mathrm{KBr}$ gradient, as described in Material and Methods.

The lipid composition of adult $C$. maculatus $L p$ is given in Figure 3. Hydrocarbons, triacylglycerol, free fatty acids, and 1,3-diacylglycerol were the main neutral lipids (Figure $3 \mathrm{~A}$ ), whereas phosphatidylserine, phosphatidylcholine and phosphatidylethanolamine were the major phospholipids (Figure 3B). The lipid composition of larval Lp showed
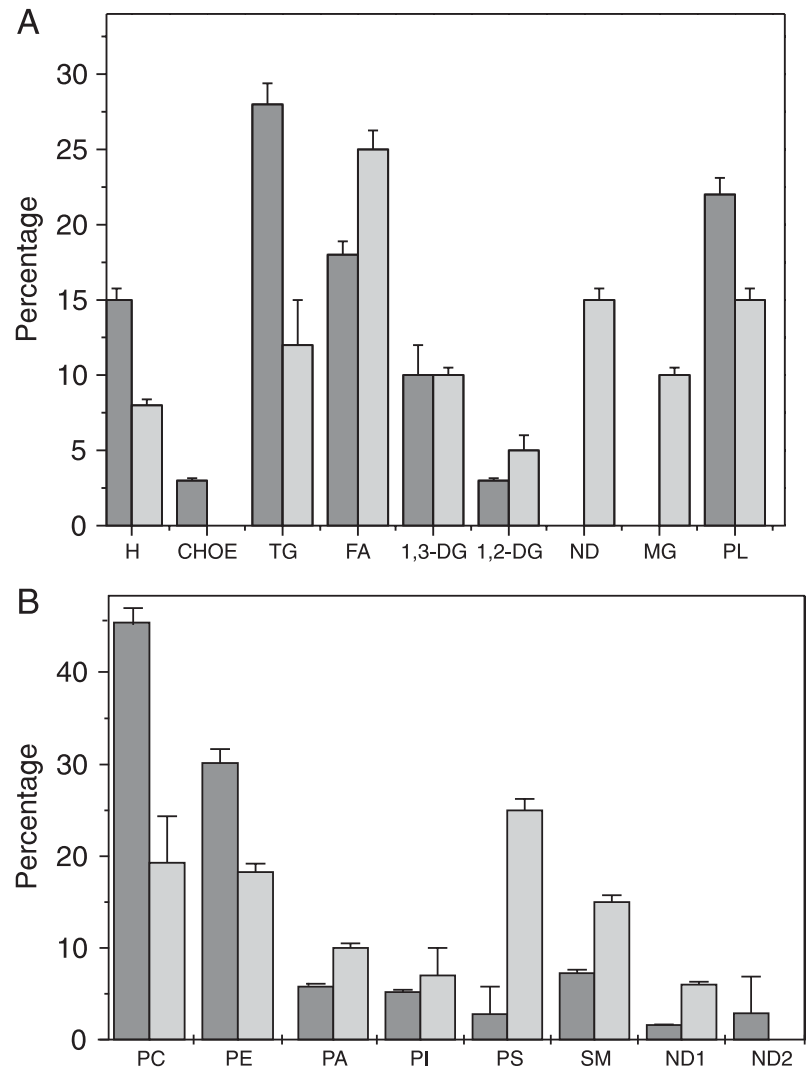

Figure 3. Lipid analysis of Callosobruchus maculatus lipophorins (Lps). Two milligrams of purified Lp from adults (dark gray columns) and larvae (light gray columns) were subjected to lipid extraction. The neutral lipids (A) and phospholipids (B) were analyzed by thin-layer chromatography as described in Material and Methods. The content of each class of lipid was estimated by densitometry and plotted as a percentage. The vertical bars represent the SEM for four determinations. $\mathrm{CHOE}=$ cholesterolester; 1,2-DG = 1,2-diacylglycerol; 1,3-DG = 1,3-diacylglycerol; $\mathrm{FA}=$ fatty acids; $\mathrm{H}=$ hydrocarbons; $\mathrm{MG}=$ monoacylglycerol; ND = non-determined; $\mathrm{PA}=$ phosphatidic acid; $\mathrm{PC}=$ phosphatidy $\mathrm{I}-$ choline; $\mathrm{PE}=$ phosphatidylethanolamine; $\mathrm{PI}=$ phosphatidylinositol; $\mathrm{PL}=$ phospholipids; $\mathrm{PS}=$ phosphatidylserine; $\mathrm{SM}=$ sphingomyelin; TG = triacylglycerol. slight differences compared to adult Lp. In the larval Lp, we observed free fatty acids, triacylglycerol and hydrocarbons (Figure 3A), and the major phospholipids were phosphatidylcholine, phosphatidylethanolamine and sphingomyelin (Figure 3B).

In order to determine the source of the relatively elevated hydrocarbon content found in both Lps, the total lipid contents of the larval homogenate and of the cowpea seeds were analyzed (Figure 4). TLC revealed that triacylglycerol, fatty acids and diacylglycerol were the most abundant lipids in the larval homogenate (Figure 4B). In cowpea seeds, triacylglycerol, sterols, phospholipids, and fatty acids predominated. Diacylglycerol was also detected, but in minor amounts (Figure 4A).

Receptor-mediated internalization of molecules is an energy-dependent active process and is significantly reduced at lower temperatures (24). We examined the uptake of ${ }^{125} \mathrm{I}$-labeled $\mathrm{Lp}$ in adults at $28^{\circ}$ and $4^{\circ} \mathrm{C}$. At $28^{\circ} \mathrm{C}$, the
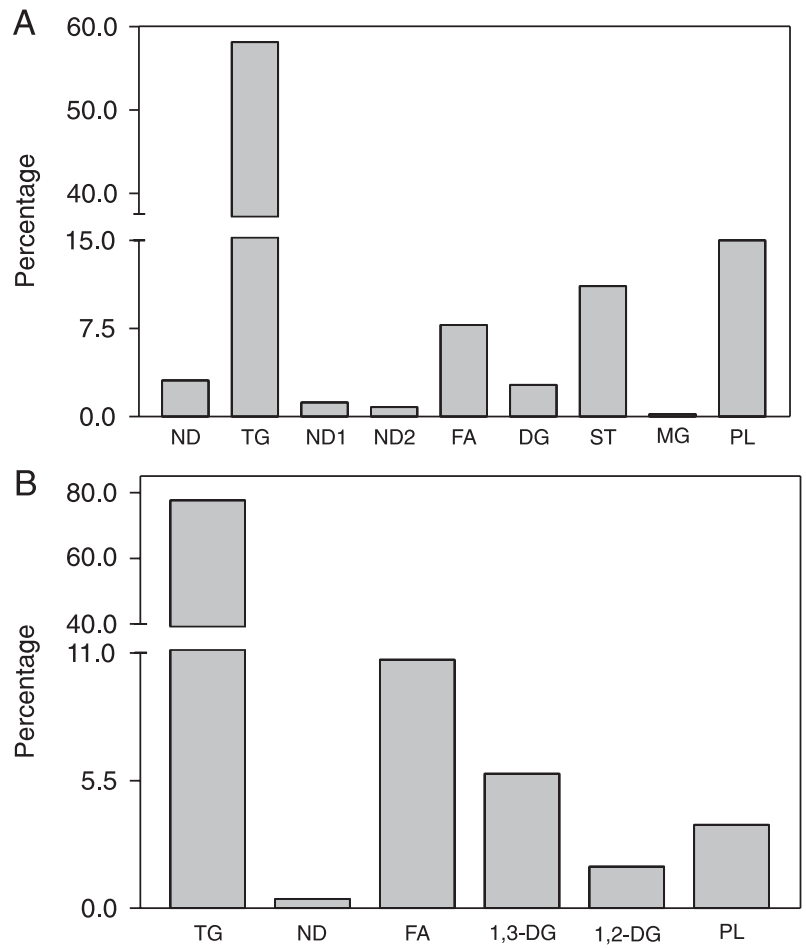

Figure 4. Lipid composition of total homogenates of cowpea seeds (A) and Callosobruchus maculatus larvae (B). Two milligrams of total homogenates was subjected to lipid extraction as described in Material and Methods. The extracted lipids were separated by thin-layer chromatography and the content of each lipid was measured by densitometry. The vertical bars represent the SEM for four determinations. DG = total diacylglycerol $(1,2-$ $D G+1,3-D G) ; F A=$ fatty acids; $H=$ hydrocarbons; $M G=$ monoacylglycerol; ND = non-determined; $\mathrm{PL}=$ phospholipids; $\mathrm{ST}=$ sterols; $\mathrm{TG}$ = triacylglycerol. 
ovaries were able to take up Lp. At $4^{\circ} \mathrm{C}$, no lipid uptake was observed (Figure 5). Taken together, these results demonstrate that $\mathrm{Lp}$ internalization by developing eggs in $C$. maculatus is an energy-dependent active process.

To confirm the lipid transfer to ovaries, vitellogenic females were injected with lipophorin fluorescently labeled with phospholipids (Texas Red-PE; Figure 6B) or a fatty-

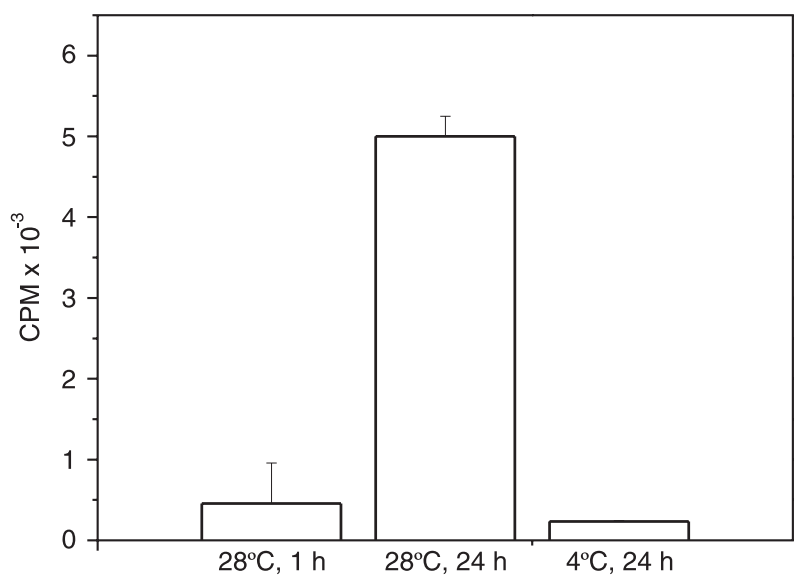

Figure 5. 125/-lipophorin uptake by Callosobruchus maculatus ovaries. Vitellogenic females were injected with ${ }^{125}$-lipophorin at $28^{\circ}$ or $4^{\circ} \mathrm{C}$. After 1 and $24 \mathrm{~h}$, the ovaries were isolated and the radioactivity was estimated by gamma counting. The vertical bars represent the SEM for four determinations. Other experimental details are described in Material and Methods. CPM = counts per minute.

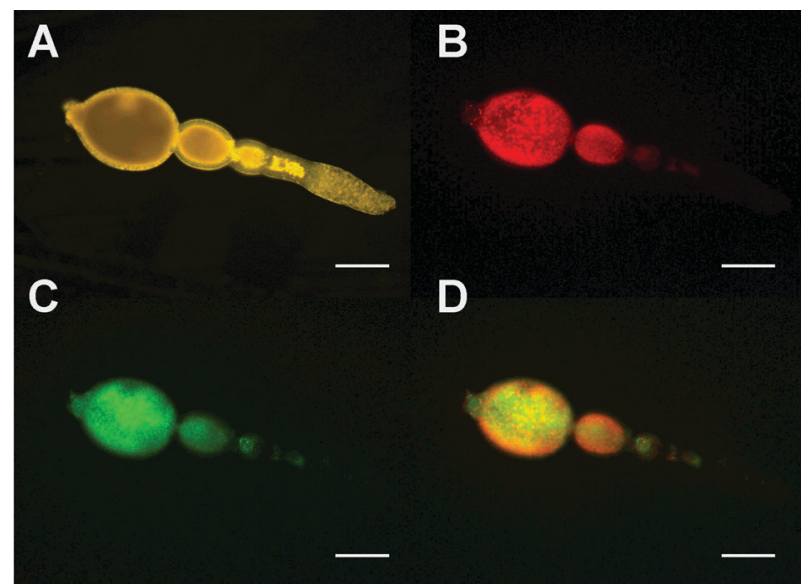

Figure 6. Visualization of lipid uptake by Callosobruchus maculatus ovary. Vitellogenic females were injected with lipoprotein labeled with fluorescent fatty acids (green) or phospholipids (red) shortly after emergence. After $24 \mathrm{~h}$, the developing oocytes were dissected and examined with a confocal microscope. Scale bar = $100 \mu \mathrm{m}$. $A$, Phase-contrast of an ovarian follicle; $B$, localization of phospholipids; $C$, localization of fatty acids; $D$, merged image of $B$ and $C$. acid analog (BODIPY-FA; Figure 6C). One day later the ovaries were excised and the fluorescence distribution was determined. In agreement with the results obtained using ${ }^{125} \mathrm{I}-\mathrm{Lp}$, we found that the ovaries of C. maculatus were able to take up lipophorin.

\section{DISCUSSION}

The biochemical characterization of purified Lps is an important step toward understanding the process of lipid utilization in insects. In the present study, we purified and partially characterized two Lps from the cowpea weevil $C$. maculatus. Radio- and fluorescent-labeled Lp was used to investigate its transport to the ovaries.

Lps from adults and larvae of $C$. maculatus were isolated by a single-step $\mathrm{KBr}$ gradient ultracentrifugation. In this gradient, both Lps floated to the top of each tube, free of contaminants (Figure 1). The Lps obtained from adults and larvae consisted of two apoproteins (apoLp-I and apoLp-II) of molecular masses similar to those from other species (25). Larval Lp contains little of the smallest apolipoprotein (apoLp-III; Figure 2D) while adult Lp contains none of this form. ApoLp-III has been found in adults of various insect species $(26,27)$. In Manduca sexta and Locusta migratoria, this apolipophorin is involved in the molecular changes that Lp undergoes during flight; as a result, Lp particles acquire a greater capacity for carrying lipids from fat body to flight muscles $(2,6,28)$. These changes are regulated by the adipokinetic hormone (5). Adults of $C$. maculatus seldom fly, and never for long distances; this could be the reason for the absence of apoLp-III in adult Lp.

A second $\mathrm{KBr}$ gradient ultracentrifugation using the $\mathrm{Lp}$ samples showed a density of $1.12 \mathrm{~g} / \mathrm{mL}$ for adult $L p$ and of $1.14 \mathrm{~g} / \mathrm{mL}$ for larval Lp (Figure 2A). These densities are close to the values reported for high-density $L p$ in other insect species (26). The Lp from adults is especially poor in lipids, which make up only about $34 \%$ of its total mass, whereas to the larval $L p$ was $55 \%$ (Table 1 ). This difference in lipid content could be responsible for the higher molecular mass (Figure 2C) and the lower density (Figure $2 A)$ of the larval Lp compared to the adult, since no apoLpIII was detected in either Lp.

Interestingly, our study indicates the presence of hydrocarbons associated with C. maculatus Lp. However, no significant amount of hydrocarbons was found in total larval homogenate or in cowpea seeds, supporting the concept that hydrocarbons are mostly synthesized during adulthood, presumably at the oenocyte level, and transported by $L p$ to the sites of deposition, including the epicuticle and ovaries $(3,29)$.

In the malaria vector Anopheles gambiae (30), in the 
cockroaches Blattella germanica (31) and Periplaneta americana (32) and in the Colorado potato beetle Leptinotarsa decemlineata (33), hydrocarbons are also the major lipid class associated with lipophorin particles.

A structural model of cockroach and locust lipophorins has already been proposed (34). It is composed of three radially symmetrical layers. The outer surface contains phospholipids and apoLp-I, the middle layer consists of diacylglycerol and apoLp-II and the central core is composed of hydrocarbons. Based on its low diacylglycerol content, it would be interesting to study lipophorin by physical methods in order to determine its structural organization.

C. maculatus Lp stains positively with the periodic acidSchiff reagent for the presence of carbohydrates (data not shown), and mannose is present as the main monosaccharide in the particle (Figure $2 \mathrm{~B}$ ). It is possible that glycosylation of $L p$ has an important role in folding and subunit assembly to achieve the mature protein in the hemolymph and ovary. Glycosylation is known to increase the solubility of proteins (35). Thus, the mannose content of $C$. maculatus Lp could have a significant role in keeping this large, hydrophobic protein in the hemolymph, improving lipid transport to the tissues.

During insect oogenesis, oocytes accumulate large amounts of lipids, which are supplied by means of Lpselective lipid transport $(9,30)$. However, during lipid transfer to Anopheles gambiae oocytes by Lp, lipid accumulation occurs simultaneously with the deposition of the protein moiety inside yolk granules through endocytosis (30). This finding is not in agreement with the general idea of $L p$ as a reusable shuttle for lipids in insects.

Receptor-mediated lipoprotein endocytosis has been studied in mammals and insects. In mammals, LDL particles are internalized upon binding to LDL receptors, which are transmembrane proteins (36). Genes for similar receptors have been cloned and sequenced from $L$. migratoria (37), Galleria mellonella (38) and A. aegypti (39). Recently, by transforming the human LDL receptor gene into insect cells, Van Hoof et al. (40) demonstrated that an endocytic pathway for Lp uptake does exist in insects. However, no endocytic uptake of $L p$ has been directly observed in insect oocytes.

Here we provide direct evidence of endocytic uptake of $\mathrm{Lp}$ in live oocytes of $C$. maculatus. Clearly, lipids from Lp accumulated in the yolk granules (Figure 6). During Lp endocytosis by oocytes, we observed a staining pattern which is similar to the LDL receptor-transfected insect cells (40). This result, together with the temperature dependence of the process, indicates Lp endocytic uptake by $C$. maculatus oocytes. Whether Lp-mediated lipid transfer to
C. maculatus oocytes acts as a reusable shuttle remains to be investigated. Further investigation of the mechanism of lipid delivery to the insect oocytes may lead to the identification of targets that can control the density of pest insects and their impact on losses of seeds in storage.

\section{ACKNOWLEDGMENTS}

We express our gratitude to Dr. Maurício Salles, Universidade Federal do Rio Grande do Norte, for the insect donation for starting our colony and to Lilian Soares da Cunha Gomes and Heloisa Coelho for excellent technical assistance.

\section{REFERENCES}

1. Silva CP, Terra WR, Lima RM. Differences in midgut serine proteinases from larvae of the bruchid beetles Callosobruchus maculatus and Zabrotes subfasciatus. Arch Insect Biochem Physiol 2001; 47: 18-28.

2. van der Horst DJ, van Hoof $D$, van Marrewijk WJ, Rodenburg KW. Alternative lipid mobilization: the insect shuttle system. Mol Cell Biochem 2002; 239: 113-119.

3. Chino H. Lipid transport: biochemistry of hemolymph lipophorin. Comprehensive insect physiology, biochemistry and pharmacology. Pergamon Press, Oxford: 1985.

4. Kawooya JK, Keim PS, Ryan RO, Shapiro JP, Samaraweera P, Law JH. Insect apolipophorin III. Purification and properties. J Biol Chem 1984; 259: 10733-10737.

5. Blacklock BJ, Ryan RO. Hemolymph lipid transport. Insect Biochem Mol Biol 1994; 24: 855-873.

6. Soulages JL, Wells MA. Metabolic fate and turnover rate of hemolymph free fatty acids in adult Manduca sexta. Insect Biochem Mol Biol 1994; 24: 79-86.

7. Engelmann F. Insect vitellogenin: identification, biosynthesis and role in vitellogenesis. Adv Insect Physiol 1979; 14: 49-108.

8. Chino H, Downer RG, Takahashi K. The role of diacylglycerol-carrying lipoprotein I in lipid transport during insect vitellogenesis. Biochim Biophys Acta 1977; 487: 508-516.

9. Kawooya JK, Law JH. Role of lipophorin in lipid transport to the insect egg. J Biol Chem 1988; 263: 8748-8753.

10. Kawooya JK, Osir EO, Law JH. Uptake of the major hemolymph lipoprotein and its transformation in the insect egg. $J$ Biol Chem 1988; 263: 8740-8747.

11. Lowry OH, Rosenbrough NJ, Farr AL, Randall RJ. Protein measurement with the Folin phenol reagent. $J$ Biol Chem 1951; 193: 265-275.

12. Laemmli UK. Cleavage of structural proteins during the assembly of the head of bacteriophage T4. Nature 1970; 227: 680-685.

13. Davis BJ. Disc electrophoresis II. Methods and application to human serum proteins. Ann N Y Acad Sci 1964; 124: 404-427.

14. Nichols AV, Krauss RM, Musliner TA. Nondenaturing polyacrylamide gradient gel electrophoresis. Methods Enzymol 1986; 128: 417-431.

15. Bligh EG, Dyer WJ. A rapid method of total lipid extraction and purification. Can J Biochem Physiol 1959; 37: 911-917.

16. Vogel CW, Doizaki WM, Zieve L. Rapid thin-layer chromato- 
graphic separation of phospholipids and neutral lipids of serum. J Lipid Res 1962; 3: 138-140.

17. Yavin E, Zutra A. Separation and analysis of 32P-labeled phospholipids by a simple and rapid thin-layer chromatographic procedure and its application to cultured neuroblastoma cells. Anal Biochem 1977; 80: 430-437.

18. Ruiz JL, Ochoa B. Quantification in the subnanomolar range of phospholipids and neutral lipids by nanodimensional thin layer chromatography and image analysis. J Lipid Res 1997; 38: $1482-1489$.

19. Dubois M, Gilles KA, Hamilton JK, Rebers PA, Smith F. Colorimetric method for the determination of sugars. Analyt Chem 1956; 28: 350-354.

20. Mourao PA, Pereira MS, Pavao MS, Mulloy B, Tollefsen DM, Mowinckel MC, et al. Structure and anticoagulant activity of a fucosylated chondroitin sulfate from echinoderm. Sulfated fucose branches on the polysaccharide account for its high anticoagulant action. J Biol Chem 1996; 271: 23973-23984.

21. Coelho HS, Atella GC, Moreira MF, Gondim KC, Masuda H. Lipophorin density variation during oogenesis on Rhodnius prolixus. Arch Insect Biochem Physiol 1997; 35: 301-313.

22. Martin-Nizard F, Richard B, Torpier G, Nouvelot A, Fruchart JC, Duthilleul P, et al. Analysis of phospholipid transfer during HDL binding to platelets using a fluorescent analog of phosphatidylcholine. Thromb Res 1987; 46: 811-825.

23. Atella GC, Shahabuddin M. Differential partitioning of maternal fatty acid and phospholipid in neonate mosquito larvae. J Exp Biol 2002; 205: 3623-3630.

24. Goldstein JL, Basu SK, Brunschede GY, Brown MS. Release of low density lipoprotein from its cell surface receptor by sulfated glycosaminoglycans. Cell 1976; 7: 85-95.

25. Gondim KC, Oliveira PL, Masuda H. Lipophorin and oogenesis in Rhodnius prolixus: transfer of phospholipids. J Insect Physiol 1989; 35: 19-27.

26. Ryan RO, Schmidt JO, Law JH. Chemical and immunological properties of lipophorin: an insect lipoprotein. Arch Insect Biochem Physiol 1984; 1: 375-383.

27. Van der Horst DJ, Van Doorn JN, Beenakkers AMTh. Hormone induced rearrangement of locust haemolymph lipoproteins: the involvement of glycoprotein $\mathrm{C}_{2}$. Insect Biochem 1984; 14: 495-504.

28. Ryan RO, van der Horst DJ. Lipid transport biochemistry and its role in energy production. Annu Rev Entomol 2000; 45: 233-260.

29. Schal C, Sevala VL, Young HP, Bachmann JAS. Synthesis and transport of hydrocarbons: cuticle and ovary as target tissues. Am Zool 1998; 38: 382-393.

30. Atella GC, Silva-Neto MA, Golodne DM, Arefin S, Shahabuddin M. Anopheles gambiae lipophorin: characterization and role in lipid transport to developing oocyte. Insect Biochem Mol Biol 2006; 36: 375-386.

31. Sevala VL, Shus S, Ramaswamy SB, Schal C. Lipophorin of female Blattella germanica (L.): characterization and relation to hemolymph titers of juvenile hormone and hydrocarbons. J Insect Physiol 1999; 45: 431-441.

32. Chino H, Katase H, Downer RG, Takahashi K. Diacylglycerol-carrying lipoprotein of hemolymph of the American cockroach: purification, characterization, and function. $J \mathrm{Li}$ pid Res 1981; 22: 7-15.

33. Katagiri C, Sato M, de Kort S, Katsube Y. Structure of
Colorado potato beetle lipophorin: differential scanning calorimetric and small-angle X-ray scattering studies. Biochemistry 1991; 30: 9675-9681.

34. Katagiri C, Sato M, Tanaka N. Small-angle X-ray scattering study of insect lipophorin. J Biol Chem 1987; 262: 1585715861.

35. Jaenicke R. Protein stability and molecular adaptation to extreme conditions. Eur J Biochem 1991; 202: 715-728.

36. Hussain MM, Strickland DK, Bakillah A. The mammalian low-density lipoprotein receptor family. Annu Rev Nutr 1999; 19: 141-172.

37. Dantuma NP, Potters M, De Winther MP, Tensen CP, Kooiman FP, Bogerd J, et al. An insect homolog of the vertebrate very low density lipoprotein receptor mediates endocytosis of lipophorins. J Lipid Res 1999; 40: 973-978.

38. Lee CS, Han JH, Kim BS, Lee SM, Hwang JS, Kang SW, et al. Wax moth, Galleria mellonella, high density lipophorin receptor: alternative splicing, tissue-specific expression, and developmental regulation. Insect Biochem Mol Biol 2003; 33: 761-771.

39. Cheon HM, Seo SJ, Sun J, Sappington TW, Raikhel AS. Molecular characterization of the VLDL receptor homolog mediating binding of lipophorin in oocyte of the mosquito Aedes aegypti. Insect Biochem Mol Biol 2001; 31: 753-760.

40. van Hoof $D$, Rodenburg KW, van der Horst DJ. Receptormediated endocytosis and intracellular trafficking of lipoproteins and transferrin in insect cells. Insect Biochem Mol Biol 2005; 35: 117-128. 